AUTHOR:

Pieter B. Kotzét,2,3 iD

\section{AFFILIATIONS:}

${ }^{1}$ South African National Space Agency, Space Science, Hermanus, South Africa

${ }^{2}$ Centre for Space Research, North-West University, Potchefstroom, South Africa ${ }^{3}$ Physics Department, Stellenbosch University, Stellenbosch, South Africa

CORRESPONDENCE TO: Pieter Kotzé

EMAIL:

pkotze@sansa.org.za

\section{DATES:}

Received: 13 Aug. 2019

Revised: 28 Jan. 2020

Accepted: 10 Mar. 2020

Published: 29 July 2020

\section{HOW TO CITE:}

Kotzé PB. Identification of solar periodicities in southern African baobab $\delta^{13} \mathrm{C}$ record. S Afr J Sci. 2020;116(7/8), Art. \#6813, 5 pages. https://doi.org/10.17159/ sajs.2020/6813

\section{ARTICLE INCLUDES:}

囚 Peer review

$\square$ Supplementary material

\section{DATA AVAILABILITY:}

$\square$ Open data set

凶 All data included

$\square$ On request from author(s)

$\square$ Not available

$\square$ Not applicable

EDITOR:

Yali Woyessa iD

\section{KEYWORDS:}

tree ring, carbon isotope data, spectral analysis, solar influences, climate variability

\section{FUNDING:}

None

\title{
Identification of solar periodicities in southern African baobab $\delta^{13} \mathrm{C}$ record
}

\begin{abstract}
Spectral analysis using wavelet, Lomb-Scargle and maximum entropy techniques of the proxy rainfall record of northeastern South Africa based on annual carbon isotope $\left(\delta^{13} \mathrm{C}\right)$ data obtained from baobab trees for the period $1600 A D-2000 A D$ show clear evidence of the presence of characteristic solar periodicities. Solar periodicities that were identified above the $95 \%$ confidence level include the $\sim 11$-year Schwabe cycle, the $\sim 22$-year Hale cycle as well as the $80-110$-year Gleissberg cycle. A Morlet wavelet analysis of the $\delta^{13} \mathrm{C}$ data between $1600 \mathrm{AD}$ and $1700 \mathrm{AD}$ shows the effect of the Maunder sunspot minimum on both the Schwabe and Hale cycles during this time.

\section{Significance:}

A spectral analysis of $\delta^{13} \mathrm{C}$ baobab tree ring data for southern Africa between $1600 \mathrm{AD}$ and $2000 \mathrm{AD}$ is presented. The results show - for the first time - that the $\delta^{13} \mathrm{C}$ time series contains the 11-year Schwabe, 22-year Hale as well as the 80-110-year Gleissberg solar periodicities. In addition, the influence of the Maunder sunspot minimum between $\sim 1650 \mathrm{AD}$ and $1715 \mathrm{AD}$ could also be clearly identified in the $\delta^{13} \mathrm{C}$ data for the first time. These findings are of significant importance to investigations of solar influences on climate variability.
\end{abstract}

\section{Introduction}

Carbon isotope ratios have been used in the literature ${ }^{1}$ by several palaeoclimate researchers as a proxy for rainfall in a specific region where data were made available by tree ring investigations. During the process of photosynthetic absorption of atmospheric $\mathrm{CO}_{2}$ by trees and plants, active discrimination occurs against ${ }^{13} \mathrm{CO}_{2}$ in favour of ${ }^{12} \mathrm{CO}_{2}{ }^{2}$ During periods of high rainfall, rapid exchange of $\mathrm{CO}_{2}$ with the atmosphere and trees takes place. During periods of low rainfall, on the other hand, the amount of $\mathrm{CO}_{2}$ available for photosynthesis is restricted to only that inside leaves. Therefore, in regions of low rainfall, like southern Africa, lower $\delta^{13} \mathrm{C}$ values are associated with wetter conditions, and higher $\delta^{13} \mathrm{C}$ values are associated with drier conditions during the growth of the wood. ${ }^{3}$ In order to link carbon isotope ratios to rainfall, one is restricted to trees that only rely on precipitation as a water source. Carbon ratios from the African baobab (Adansonia digitata L.) have shown strong correlation with summer rainfall patterns in southern Africa in a previous study. ${ }^{4}$

The sun is a variable star that exhibits changes on multiple spatial and temporal scales, and is the most important source of energy for the earth's climate system (see for example a review on this topic by Gray et al. ${ }^{5}$ and the references therein). Solar activity is characterised by periodicities and cycles that vary on a variety of timescales. The most important periodicities are the $\sim 11$-year sunspot cycle (also known as the Schwabe cycle), the $\sim 22$-year magnetic cycle (also known as the Hale cycle), the 80-110-year Gleissberg cycle as well as the $\sim 205$-year De Vries cycle. These periodicities of solar origin have been identified in several tree ring records and cosmogenic data such as ${ }^{10} \mathrm{Be}$ and ${ }^{14} \mathrm{C}$ (see for example the review by Usoskin ${ }^{6}$ and the references therein). Convincing evidence for solar influences on weather and climate has been found in the last $\sim 150$ years (Hoyt and Schatten ${ }^{7}$ and references therein). Souza Echer et al. ${ }^{8}$ found a clear correlation in the 22 -year periodicity between global air surface temperature and sunspot number in the interval 1880-2000. Although solar signals have been detected in climate records (e.g. Beer et al. ${ }^{9}$ ), one should keep in mind that climate and rainfall is a non-linear system and that several forces are involved in the process. Apart from the direct and indirect effects of solar irradiance (total solar irradiance and ultraviolet), particle radiation effects (solar energetic particles and cosmic rays) also have an effect on the troposphere (see Figure 21 in Gray et al..$^{5}$ ). Rigozo et al..$^{10}$ investigated the solar activity signals in tree ring data in Chile over a period of $\sim 400$ years, employing spectral analysis techniques. They found clear evidence for the presence of solar activity: Schwabe ( 11-year), Hale ( 22-year), fourth-harmonic of the 208-year De Vries ( $\sim 52$-year) and Gleissberg ( $\sim 80$-year) cycles. Several investigations have indicated that solar variations had an effect on pre-industrial climate throughout the Holocene (the warm interval since the last ice age). These studies have been done in several parts across the globe and utilised a large variety of palaeoclimate proxies. The reader is referred to the recent review by Lockwood ${ }^{11}$. An interesting finding by McKinnell and Crawford ${ }^{12}$ is the long-term lunar-induced 9.3-year and 18.6-year cycles in the temperature records in some regions over a 400 -year period. A wavelet analysis of centennial (1895-1994) rainfall data in southern Brazil by Souza Echer et al. ${ }^{13}$ confirmed the existence of strong 8.9-, 11.7- and 24.9-year periodicities. ${ }^{14} \mathrm{C}$ time series studies on tree growth rings from Bashkiria (Russia) by Kocharov et al. ${ }^{14}$ revealed periods close to $21,9.4$ and 13.5 years using advanced spectral analysis methods. Damon et al. ${ }^{15}$, who also studied a time series of $\delta^{14} \mathrm{C}$ in tree rings, for the time interval between $1065 \mathrm{AD}$ and $1250 \mathrm{AD}$, confirmed these results. They also detected a period of $\sim 52$ years and attributed it to the fourth harmonic of the Suess or De Vries cycle. The climate of southern Africa is to a large extent semiarid. ${ }^{16}$ Except for the southern coastal area, the southern African region receives almost all its rainfall in summer. A characteristic feature of the southern African rainfall record is the pronounced $\sim 80$-year cycle that can be traced back 3500 years. ${ }^{16}$

In this investigation, $\delta^{13} \mathrm{C}$ measurements obtained from the Pafuri 1000 -year-old baobab trees ${ }^{17}$ were analysed between the years $1600 \mathrm{AD}$ and $2000 \mathrm{AD}$ to identify the presence of possible solar periodicities. Spectral analysis methods such as wavelets ${ }^{18}$, Lomb-Scargle ${ }^{19,20}$ and maximum entropy ${ }^{21}$ were used to obtain statistically significant results above the $95 \%$ confidence level. In addition, a Morlet ${ }^{22}$ wavelet analysis of $\delta^{13} \mathrm{C}$ between $1600 \mathrm{AD}$ and 
$1700 \mathrm{AD}$ was performed to investigate the variation in the strengths of, particularly, the Schwabe and Hale cycles during the Maunder sunspot minimum period of 1645-1715 AD (Eddy). ${ }^{23}$

\section{Data and method of analysis}

Woodborne et al. ${ }^{17}$ did a carbon isotope analysis of four South African baobab trees located in the Pafuri area $\left(22^{\circ} 22.925^{\prime} \mathrm{S}, 31^{\circ} 13.145^{\prime} \mathrm{E}\right.$; $22^{\circ} 26.647^{\prime} \mathrm{S}, 31^{\circ} 04.745^{\prime} \mathrm{E} ; 2^{\circ} 15.765^{\prime} \mathrm{S}, 31^{\circ} 33.309^{\prime} \mathrm{E}$; $22^{\circ} 24.352^{\prime} \mathrm{S}$, $31^{\circ} 16.676{ }^{\prime} \mathrm{E}$ ) in order to obtain a proxy for rainfall in this region. A map of southern Africa showing the location of the trees is given in Figure 1.

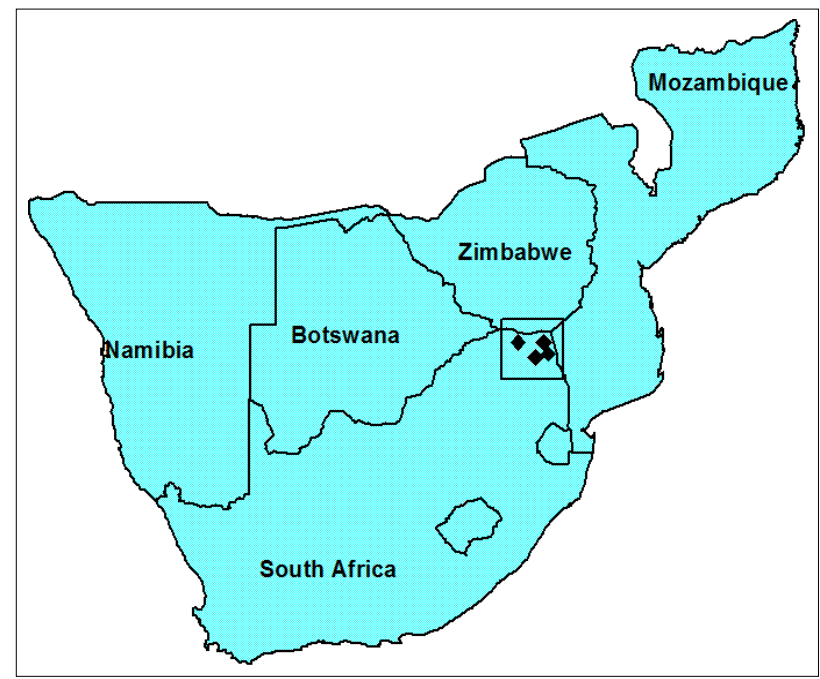

Figure 1: A map of southern Africa showing the location of the four baobab trees (inside the square area as indicated) whose $\delta^{13} \mathrm{C}$ data were used in this study.

Samples obtained were large enough to separate individual ring structures at 1-year intervals. Woodborne et al. ${ }^{17}$ subsequently performed an accelerator mass spectrometry radiocarbon analysis of these samples and calibrated the dates using well-known standards and procedures. They used the extracted $\delta^{13} \mathrm{C}$ data to confirm abnormal dry conditions during the Little Ice Age, particularly during 1635 and 1695. The $\delta^{13} \mathrm{C}$ data were obtained from Woodborne et al..$^{24}$ (http://www.ncdc. noaa.gov/paleo/study/17995). Figure 2 shows the data between AD 1600 and 2000 utilised in this investigation.

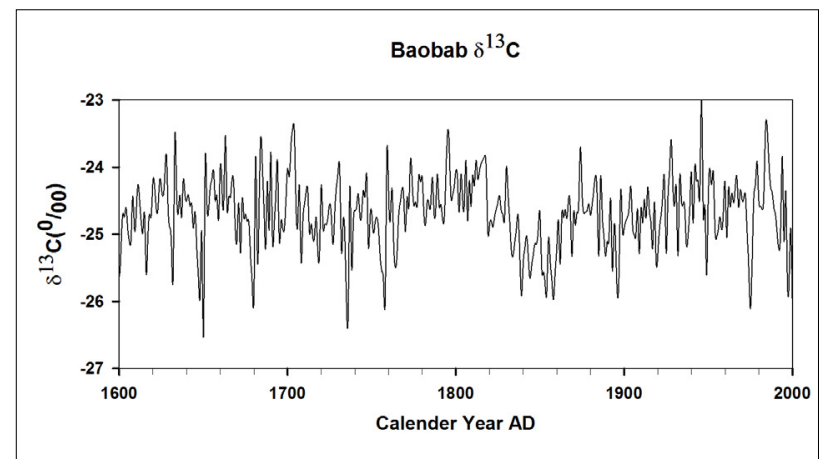

Figure 2: A plot showing the $\delta^{13} \mathrm{C}$ tree ring data at annual intervals between $1600 \mathrm{AD}$ and $2000 \mathrm{AD}$ as obtained by Woodborne et al. ${ }^{17}$ from baobab trees in the Pafuri region of southern Africa.

Three spectral analysis approaches were employed in this investigation to perform a spectral analysis of $\delta^{13} \mathrm{C}$ time series, namely the wavelet, the Lomb-Scargle periodogram method, and the maximum entropy method, in order to identify characteristic periodicities above the $95 \%$ confidence level. Wavelet analysis is used extensively to decompose a time series into time-frequency space and to establish the modes of variability, particularly when the time series under investigation contains non-stationary power at different periods. As the wavelet transform is a localised transform in both space (time) and frequency, this particular property can be usefully applied to extract information from the signal, which is not possible with Fourier techniques (Daubechies). ${ }^{25}$ All graphs and plots in this paper were produced using the SigmaPlot (www.systat.com) plotting package, while the contour plots were generated using the Interactive Data Language wavelet applet (http://www.exelisvis.com/ProductsServices/IDL.aspx).

\section{Results and discussion}

Morlet wavelet power spectra of order 6 were obtained by analysing the $\delta^{13} \mathrm{C}$ time series at a cadence of 1 year between $1600 \mathrm{AD}$ and $1700 \mathrm{AD}$. This was done particularly to investigate the behaviour of the Schwabe ( 11 -year sunspot) cycle as well as the Hale ( $\sim 22$-year magnetic) cycle with time during this interval. The results can be seen in Figure 3 below.

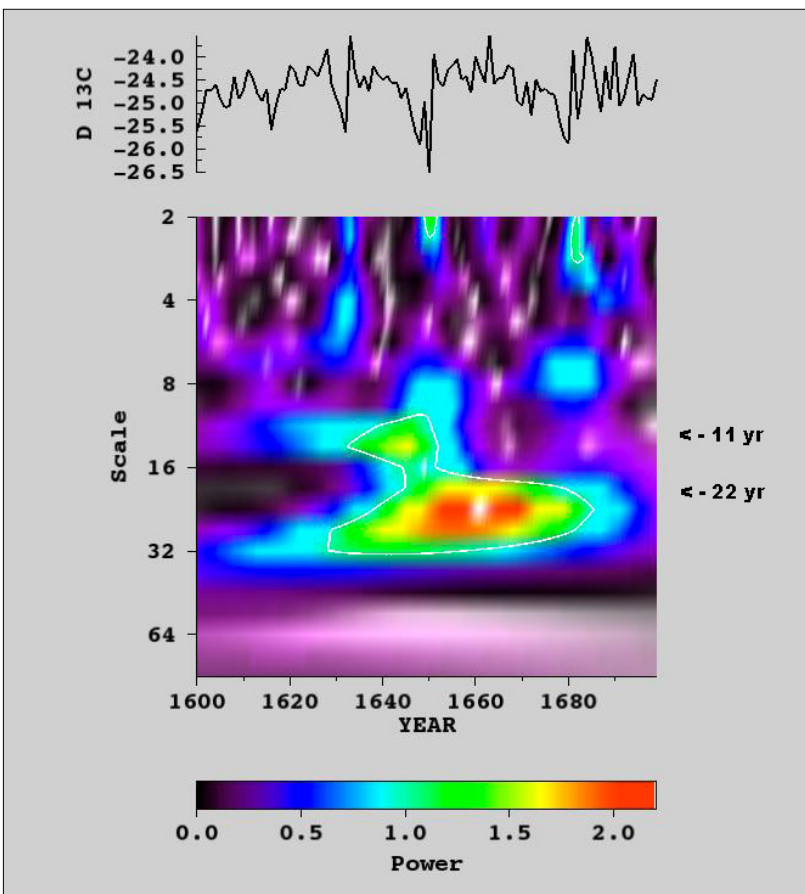

Figure 3: A Morlet wavelet power spectrum of the Pafuri $\delta^{13} \mathrm{C}$ data between $1600 A D$ and $1700 A D$, showing the behaviour of the Schwabe ( $\sim 11$-year) and Hale ( 22-year) solar periodicities during this interval. The white contour line represents the $95 \%$ confidence level. The top plot shows the annual $\delta^{13} \mathrm{C}$ data.

From Figure 3, the 11-year Schwabe sunspot cycle as well as the 22-year Hale solar magnetic cycle can be clearly identified. It is interesting to note that the 11-year sunspot cycle could only be observed between $\sim 1630 \mathrm{AD}$ and $1650 \mathrm{AD}$ above the $95 \%$ confidence level, while between $\sim 1650 \mathrm{AD}$ and $1700 \mathrm{AD}$ it disappeared completely. This particular interval coincides with the sunspot Maunder Minimum (1645-1715 AD) when no sunspots could be observed on the surface of the sun and was also known as the Little Ice Age. In the northern hemisphere, extreme cold spells were experienced during the Little Ice Age. It is quite extraordinary that a disappearance of the 11-year Schwabe cycle on the sun did indeed coincide with a similar pattern in the $\delta^{13} \mathrm{C}$ data obtained from the summer rainfall region of southern Africa. The purpose of this investigation is not to show that rainfall is influenced by the sun, but that during extreme sunspot minimum conditions like the Maunder Minimum, we observe that solar periodicities like the 11-year Schwabe period in rainfall proxy parameters such as $\delta^{13} \mathrm{C}$ can indeed disappear or become statistically insignificant. On the other hand, due to the sub-dominant role of the 11-year periodicity during the Maunder Minimum, we observe a dominant 22-year periodicity in this time, supporting observations by Mursula et al. ${ }^{26}$ Similar observations during the Maunder Minimum in solar proxies showing a dominant 22-year periodicity accompanied by 
a less-dominant Schwabe cycle have been reported by Silverman ${ }^{27}$ in aurora data and by Miyahara et al. ${ }^{28}$ in ${ }^{14} \mathrm{C}$ data.

We proceeded with the analysis of $\delta^{13} \mathrm{C}$ by performing a Lomb-Scargle spectral analysis between $1600 \mathrm{AD}$ and $2000 \mathrm{AD}$ at each 100-year interval in order to identify other prominent periodicities in the data. Results obtained are displayed in Figure 4.

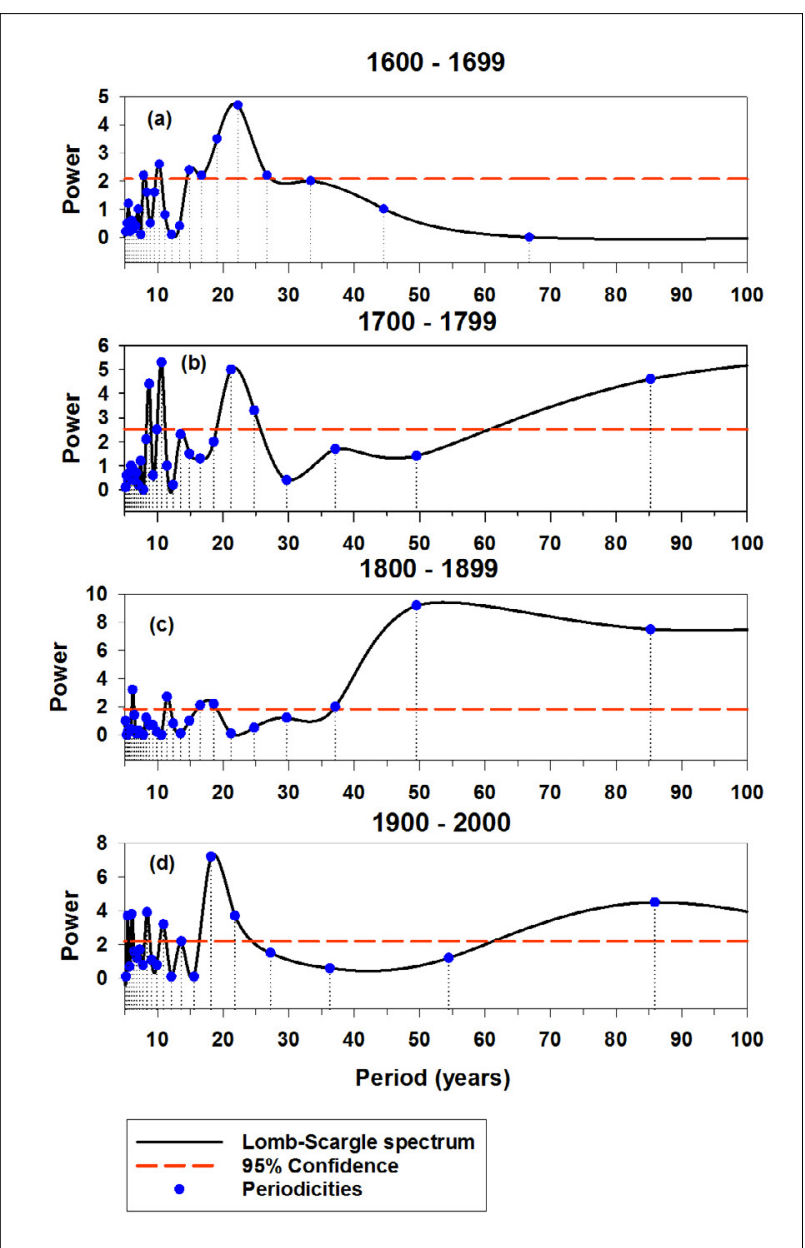

Figure 4: Lomb-Scargle spectral analysis of Pafuri baobab $\delta^{13} \mathrm{C}$ data between (a) 1600 and 1699, (b) 1700 and 1799, (c) 1800 and 1899 and (d) 1900 and 2000. The black curves are spline fits of the periodicities revealed by the Lomb-Scargle method.

From Figure 4a (and Table 1) a Lomb-Scargle analysis revealed periodicities in the $\delta^{13} \mathrm{C}$ data at $\sim 18$ and 22 years above the $95 \%$ confidence level, while the 10.3-year period is marginally statistically significant, confirming our wavelet analysis regarding the 11-year periodicity. The $\sim 18$-year period fits in with the general conclusion by Tyson et al. ${ }^{16}$ that climate variability in the 16-20-year range is a characteristic feature of southern Africa. However, one cannot exclude the possibility that this $\sim 18$-year periodicity can be linked to the lunarinduced 18.6-year cycle as reported by McKinnell and Crawford ${ }^{12}$. This 18-year cycle has been identified as a characteristic oscillation in southern African rainfall and has been extensively documented in the meteorological records. It appears predominantly in the summer rainfall tree-ring data, but could not be identified during 1700-1799 AD. Figure $4 \mathrm{~b}$, representing periodicities observed between $1700 \mathrm{AD}$ and $1799 \mathrm{AD}$, shows a resurgence of both the 11-year as well as the 22-year cycles, while we also notice with interest the appearance of an 85-year period which represents the solar Gleissberg cycle. Variability at about 80 years has been observed on a global scale. A review by Hoyt and Schatten ${ }^{7}$ summarises its presence in temperature and precipitation data sets as well as tree-ring investigations. During 1700-1799 AD, we also observed a 24.7-year as well as a 8.7-year periodicity (Table 1). These periods have also been observed in the rainfall records of southern Brazil $^{13}$ during 1894-1995. The 8.7-year period can possibly be a result of long-term, lunar-induced, 9.3-year modulation of sea-surface temperatures as reported by McKinnell and Crawford ${ }^{12}$. Periodicities identified between $1800 \mathrm{AD}$ and $1899 \mathrm{AD}$, exceeding the $95 \%$ confidence level, can be seen in Figure $4 \mathrm{c}$ and Table 1. Of particular interest is the 11-year Schwabe cycle at 12.1 years as well as the 85-year Gleissberg cycle. In addition, we also see the appearance of a 50 -year periodicity which is only observed during $1800-1899 \mathrm{AD}$. This particular periodicity has been identified by Cohen and Lintz ${ }^{29}$ as a 'shoulder' to the Gleissberg solar cycle. During 1900-2000 (Figure 4d), our Lomb-Scargle analysis not only revealed the presence of the Schwabe (at 10.9 years), Hale (at 21.7 years) and Gleissberg (at 85.9 years) solar periodicities, but also the $\sim 18$-year and $\sim 9$-year periods to be statistically significant above the $95 \%$ level. Of particular interest is that the $\sim 18$-year period has the highest amplitude/strength during 1900-2000.

As a next step to verify results obtained by wavelet and Lomb-Scargle methods, we performed a maximum entropy spectral analysis of the Pafuri baobab $\delta^{13} \mathrm{C}$ data for the time interval 1600-2000 AD. Maximum entropy results are shown in Figure 5 and summarised in Table 1.

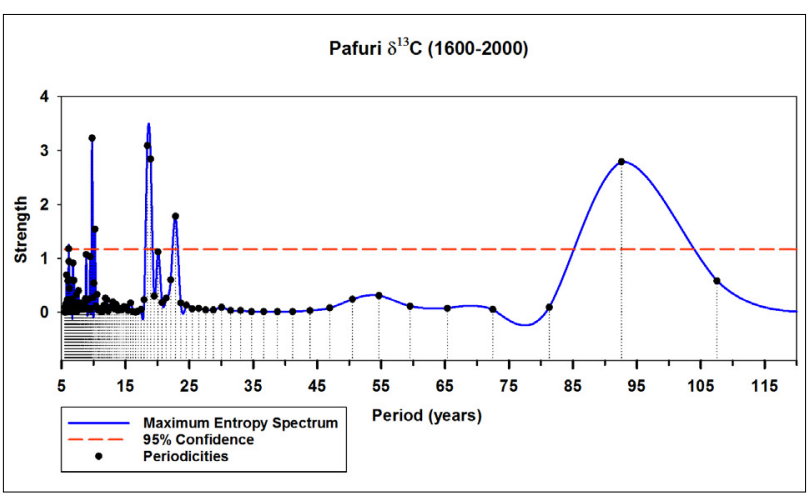

Figure 5: Maximum entropy spectral analysis of the Pafuri baobab $\delta^{13} \mathrm{C}$ data for the time period between 1600 and 2000. The blue curve is a spline fit of the identified periodicities.

From our maximum entropy analysis, we could clearly identify the 11-year Schwabe (at 10.2 years), the 22-year Hale (at 22.8 years) as well as the Gleissberg solar period (at 92.5 years) above the $95 \%$ statistically significant level. In addition, the $\sim 18$-year period which is characteristic of southern African rainfall could also be verified. These results show, particularly, that the solar periodicities identified through our spectral analysis techniques are statistically significant.

Table 1: $\quad$ All periodicities identified above the $95 \%$ confidence level during each interval between $1600 \mathrm{AD}$ and $2000 \mathrm{AD}$ using LombScargle and maximum entropy spectral analysis techniques

\begin{tabular}{c|c|c|c|c}
\hline \hline \multicolumn{4}{c|}{ Lomb-Scargle periodicities } & $\begin{array}{c}\text { Maximum entropy } \\
\text { periodicities }\end{array}$ \\
\hline \hline $\begin{array}{c}\mathbf{1 6 0 0}- \\
\mathbf{1 6 9 9} \text { AD }\end{array}$ & $\begin{array}{c}\mathbf{1 7 0 0}- \\
\mathbf{1 7 9 9} \text { AD }\end{array}$ & $\begin{array}{c}\mathbf{1 8 0 0}- \\
\mathbf{1 8 9 9} \text { AD }\end{array}$ & $\begin{array}{c}\mathbf{1 9 0 0 -} \\
\mathbf{2 0 0 0} \text { AD }\end{array}$ & $\mathbf{1 6 0 0 - 2 0 0 0 ~ A D ~}$ \\
\hline \hline- & 85.2 & 85.2 & 85.9 & 92.5 \\
\hline- & - & 49.5 & - & - \\
\hline 22.2 & $21.2,24.7$ & - & 21.7 & 22.8 \\
\hline $15.5,18.8$ & - & 18.1 & 18.1 & 18.4 \\
\hline 10.3 & 10.6 & 12.1 & 10.9 & 10.2 \\
\hline- & 8.7 & - & 8.4 & - \\
\hline
\end{tabular}

A cross-spectral analysis was subsequently performed to determine whether a statistically significant correlation exists between sunspot periodicities and the Pafuri $\delta^{13} \mathrm{C}$ data between $1600 \mathrm{AD}$ and $2000 \mathrm{AD}$. Cross-spectral analysis is a method to determine the common variability between two time series as a function of periodicity (frequency) and to 
determine the coherency between them. The Fortran computer program REDFIT- $X^{30}$ was used to determine the coherence between sunspot numbers and $\delta^{13} \mathrm{C}$ observations. Results obtained are shown in Figure 6.

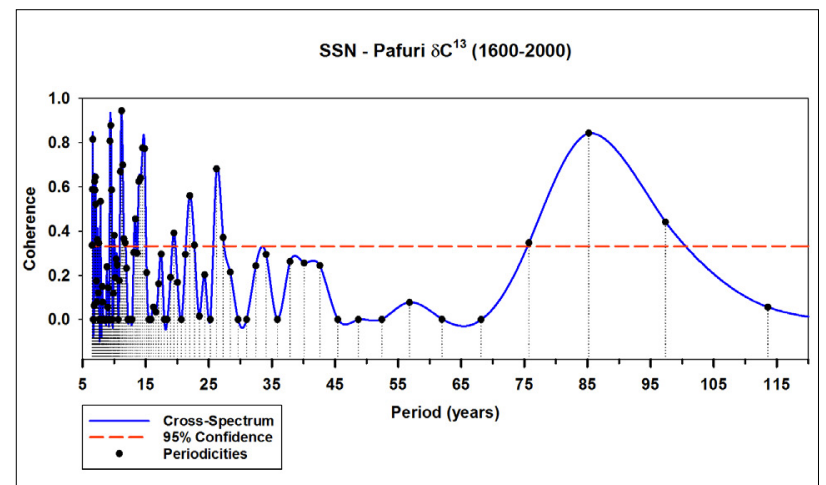

Figure 6: A cross-spectral analysis between annual mean sunspot numbers (ssn) and $\delta^{13} \mathrm{C}$ data between $1600 \mathrm{AD}$ and $2000 \mathrm{AD}$.

The cross-spectral results clearly show exceptionally strong coherence for the 11-year Schwabe cycle $(>0.9)$ as well as the 85-year Gleissberg cycle (>0.8), while coherence for the 22-year Hale cycle was at a moderate level of 0.56 . These results are all well above the $95 \%$ confidence level as displayed in Figure 6.

\section{Conclusions}

In this study, $\delta^{13} \mathrm{C}$ measurements from the Pafuri baobab trees between the years $1600 A D$ and $2000 A D$ have been analysed in order to identify the presence of possible well-known solar periodicities. Spectral analysis methods such as wavelets, Lomb-Scargle and maximum entropy were employed to obtain statistically significant results above the $95 \%$ confidence level. Results obtained show clear evidence of the presence of the 11-year Schwabe sunspot cycle, the 22-year Hale magnetic cycle as well as the 80-100-year Gleissberg solar cycle. In addition, the $\sim 18$-year period which is characteristic of southern African rainfall, could also be identified in our spectral analysis, confirming previous investigations of the rainfall pattern across this region. Previous investigations linked this periodicity to lunar-induced effects $^{12}$ on sea-surface temperatures. A Morlet wavelet analysis of $\delta^{13} \mathrm{C}$ data, particularly concentrating on the time interval between $1600 \mathrm{AD}$ and $1700 \mathrm{AD}$, revealed, in particular, that the Schwabe cycle could only be observed between $\sim 1630 A D$ and 1650 AD above the 95\% confidence level, while between $\sim 1650 \mathrm{AD}$ and $1700 \mathrm{AD}$ it disappeared completely. This particular period coincides with the sunspot Maunder Minimum period when hardly any sunspots could be identified on the surface of the sun. This period is also known as the Little Ice Age when exceptionally low temperatures were recorded in Europe. To the best of our knowledge, this is the first identification of the presence of the Maunder Minimum in $\delta^{13} \mathrm{C}$ tree-ring data in southern Africa. In order to verify our results, we further performed a cross-spectral analysis of sunspot data and $\delta^{13} \mathrm{C}$ measurements between $1600 \mathrm{AD}$ and $2000 \mathrm{AD}$. Evidence obtained from this analysis showed exceptionally strong coherence, particularly for the Schwabe and Gleissberg cycles, while a moderate coherence exists for the 22-year Hale cycle. Waple et al. ${ }^{31}$ investigated solar irradiance forcing on climate over a 200 -year period between $1650 \mathrm{AD}$ and $1850 \mathrm{AD}$ preceding the industrial era with its anthropogenic influence. This era is characterised by a wide range of solar irradiance values and includes the Maunder Minimum. The authors conclude that on multi-decadal to century timescales, solar forcing is dominated by the $\sim 90$-year Gleissberg cycle, while at decadal timescales the 11-year and 22-year solar cycles dominate.

Sundqvist et al. ${ }^{32}$ analysed a 350 -year $\delta^{18} 0$ stalagmite record from the summer rainfall region in South Africa and reported a positive correlation with regional air surface temperatures at interannual timescales. They found that during parts of the Little Ice Age, the regional temperature could have been $\sim 1.5^{\circ} \mathrm{C}$ colder than today. Prominent 22and 11-year cycles also indicated that both the solar magnetic as well as the El Nino-Southern Oscillation cycle could be important drivers of multi-decadal to interannual climate variability in southern Africa. A surface water temperature reconstruction from Antarctica ${ }^{33}$ shows similar features and a cooling of more than $2{ }^{\circ} \mathrm{C}$ between $1300 \mathrm{AD}$ and 1800 AD. These records show clear evidence that the Little Ice Age, originally identified in the northern hemisphere, also had a counterpart in the southern hemisphere. Peristykh and Damon ${ }^{34}$ did an interesting spectral analysis study of $\delta^{14} \mathrm{C}$ tree-ring data divided into intervals before, during and after the Maunder Minimum. They found that the $\sim 22$-year Hale cycle is most prominent during the Maunder Minimum, while the 11-year cycle is totally suppressed. In addition, they also reported that before the Maunder Minimum the Hale cycle had a period of 22.9 years, whereas during the minimum the cycle had two periodicities at 24 and 15.8 years, and after the minimum the Hale cycle had a period of 26 years. Our investigation also confirmed the existence of a 15.5-year periodicity during 1600-1699 AD, but periodicities observed between $\sim 25$ and 30 years were found to be below the $95 \%$ confidence level. They were therefore regarded as not statistically significant.

The results obtained in this investigation, in particular $\delta^{13} \mathrm{C}$ measurements from the Pafuri baobab trees in southern Africa between the years $1600 A D$ and $2000 A D$, provide strong evidence of the presence of solar cycles. These $\delta^{13} \mathrm{C}$ isotope measurements are regarded by palaeoclimatologists as a proxy for rainfall in a particular region. Results obtained in this investigation can be regarded as the first identification of prominent solar cycles in $\delta^{13} \mathrm{C}$ tree-ring data in southern Africa. Of particular interest is the behaviour of the Schwabe cycle during the Maunder Minimum period between 1650 AD and 1700 AD.

\section{Acknowledgements}

The author thanks the NOAA National Center for Environmental Information for archiving and making the tree ring data available. The assistance and constructive comments of two anonymous reviewers in evaluating this paper are appreciated.

\section{Conflicts of interest}

The author declares that no competing interests exist.

\section{References}

1. Norstrom E, Holmgren $\mathrm{K}$, Morth $\mathrm{CM}$. Rainfall-driven variations in $\mathrm{d} 13 \mathrm{C}$ composition and wood anatomy of Breonadia salicina trees from South Africa between AD 1375 and 1995. S Afr J Sci. 2005;101(3-4):162-168.

2. McCarroll D, Loader NJ. Stable isotopes in tree rings. Quat Sci Rev. 2004;23(7):771-801. https://doi.org/10.1016/j.quascirev.2003.06.017

3. Farquhar GD, O'Leary MH, Berry JA. On the relationship between carbon isotope discrimination and the intercellular carbon dioxide concentration in leaves. Funct Plant Biol. 1982;9(2):121-137. https://doi.org/10.1071/PP9820121

4. Robertson I, Loader NJ, Froyd CA, Zambatis N, Whyte I, Woodborne $\mathrm{S}$. The potential of the baobab (Adansonia digitata L.) as a proxy climate archive. Appl Geochem. 2006;21(10):1674-1680. https://doi.org/10.1016/j. apgeochem.2006.07.005

5. Gray LJ, Beer J, Geller M, Haigh JD, Lockwood M, Matthes K, et al. Solar Influences on Climate. Rev Geophys. 2010;48, RG4001. https://doi. org/10.1029/2009RG000282

6. Usoskin IG. A history of solar activity over millennia. Living Rev Sol Phys. 2013;10:1-94. https://doi.org/10.12942//rsp-2013-1

7. Hoyt DV, Schatten KH. The role of the sun in climate change. New York: Oxford University Press; 1997

8. Souza Echer MP, Echer E, Nordemann DJR, Rigozo NR. Multi-resolution analysis of global surface air temperature and solar activity relationship. $J$ Atmos Solar-Terrestrial Phys. 2009;71:41-44. https://doi.org/10.1016/i. jastp.2008.09.032

9. Beer J, Mende M, Stellmacher R. The role of the Sun in climate forcing. Quat Sci Rev. 2000;19:403-415. https://doi.org/10.1016/ S0277-3791(99)00072-4 
10. Rigozo NR, Nordemann DJR, Souza Echer MP, EcherE, Silva HE, Prestes A, etal. Solar activity imprints in tree ring width from Chile (1610-1991). J Atmos Solar-Terrestrial Phys. 2007;69(9):1049-1056. https://doi.org/10.1016/j. jastp.2007.03.010

11. Lockwood M. Solar induced climate effects. In: Encyclopaedia of sustainability science and technology. Berlin: Springer; 2012.

12. McKinnell SM, Crawford WR. The 18.6-year lunar nodal cycle and surface temperature variability in the northeast Pacific. J Geophys Res. 2007;112, C02002. https://doi.org/10.1029/2006JC003671

13. Souza Echer MP, Echer E, Nordemann DJR, Rigozo NR, Prestes A. Wavelet analysis of a centennial (1895-1994) southern Brazil rainfall series. Clim Change. 2008;87:489-497.

14. Kocharov GE, Ostryakov VM, Peristykh AN, Vasil'ev VA. Radiocarbon content variations and Maunder Minimum of solar activity. Sol Phys. 1995;159:381-391. https://doi.org/10.1007/BF00686539

15. Damon PE, Eastone CJ, Hughes MK, Kalin RM, Long A, Peristykh AN. Secular variation of $\delta^{14} \mathrm{C}$ during the Medieval Solar Maximum: A progress report. Radiocarbon. 1998;40(1):343-350. https://doi.org/10.1017/S00$3382220001821 X$

16. Tyson PD, Cooper GRJ, McCarthy TS. Millennial to multi-decadal variability in the climate of southern Africa. Int J Climatol. 2002;22:1105-1117. https:// doi.org/10.1002/joc.787

17. Woodborne S, Hall G, Robertson I, Patrut A, Rouault M, Loader NJ, et al. A 1000 -year carbon isotope rainfall proxy record from South African baobab trees (Adansonia digitata L.). PLoS ONE. 2015;10(5), e0124202. https://doi. org/10.1371/journal.pone.0124202

18. Torrence C, Compo GP. A practical guide to wavelet analysis. Bull Am Meteorol Soc. 1998;79:61-78.

19. Lomb NR. Least-squares frequency analysis of unequally spaced data. Astrophys Space Sci. 1976;39:447-462. https://doi.org/10.1007/BF00648343

20. Scargle JD. Studies in astronomical time series II - Statistical aspects of spectral analysis of unevenly spaced data. Astrophys J. 1982;263:835-853. https://doi.org/10.1086/160554

21. Ables JG. Maximum entropy spectral analysis. Astron Astrophys Suppl. 1974;15:383-393.
22. Morlet J, Arens G, Forgeau I, Giard D. Wave propagation and sampling theory. Geophysics. 1982;47(2):203-221. https://doi.org/10.1190/1.1441328

23. Eddy JA. The Maunder Minimum. Science. 1976;192:1189-1202. https:// doi.org/10.1126/science.192.4245.1189

24. Woodborne S, Hall G, Robertson I, Patrut A, Rouault M, Loader NJ, et al. NOAA/WDS Paleoclimatology - Pafuri, South Africa 1000 year baobab tree carbon isotope data [data set]. NOAA National Centers for Environmental Information. 2015 May 13 [cited 2020 Jan 28]. Available from: http://www. ncdc.noaa.gov/paleo/study/17995. https://doi.org/10.25921/k336-r342

25. Daubechies I. The wavelet transform, time-frequency localization and signal analysis. IEEE Trans Info Theory. 1990;36(5):961-1005. https://doi. org/10.1109/18.57199

26. Mursula K, Usoskin IG, Kovaltsov GA. Persistent 22-year cycle in sunspot activity: Evidence for a relic solar magnetic field. Sol Phys. 2001;198:51-56. https://doi.org/10.1023/A:1005218414790

27. Silverman SM. Secular variation of the aurora for the past 500 years. Rev Geophys. 1982;30:333-351. https://doi.org/10.1029/92RG01571

28. Miyahara H, Masuda K, Muraki Y, Furuzawa H, Menjo H, Nakamura T. Cyclicity of solar activity during the Maunder Minimum deduced from radiocarbon content. Sol Phys. 2004;224:317-322. https://doi.org/10.1007/s11207-005-6501-5

29. Cohen TJ, Lintz PR. Long-term periodicities in the sunspot cycle. Nature. 1974;250:398-400. https://doi.org/10.1038/250398a0

30. Ólafsdóttir KB, Schultz M, Mudelsee M. REDFIT-X: Cross-spectral analysis of unevenly spaced paleoclimate time series. Comput Geosci. 2016;91:11-18. https://doi.org/10.1016/..cage0.2016.03.001

31. Waple AM, Mann ME, Bradley RS. Long-term patterns of solar irradiance forcing in model experiments and proxy based surface temperature reconstructions. Clim Dyn. 2002;18:563-578. https://doi/10.1007/s00382-001-0199-3

32. Sundqvist HS, Holmgren K, Fohlmeister J, Zhang Q, Bar Matthews M, Spötl C, et al. Evidence of a large cooling between 1690 and $1740 \mathrm{AD}$ in southern Africa. Sci Rep. 2013;3:1767. https://doi.org/10.1038/srep01767

33. Berter NA, Mayewski NPA, Carter L. Cold conditions in Antarctica during the Little Ice Age - Implications or abrupt climate change mechanisms. Earth Planet Sci Lett. 2011;308:41-51. https://doi.org/10.1016/j.epsl.2011.05.021

34. Peristykh AN, Damon PE. Modulation of atmospheric ${ }^{14} \mathrm{C}$ concentration by the solar wind and irradiance components of the Hale and Schwabe solar sycles. Solar Phys. 1998;177:343-355. https://doi.org/10.1023/A:1004982321191 